\title{
Comparison of low-concentration carbon dioxide-enriched and tap water immersion on body temperature after passive heating
}

Keiji Hayashi* ${ }^{*}$

\begin{abstract}
Background: Because carbon dioxide $\left(\mathrm{CO}_{2}\right)$-enriched water causes cutaneous vasodilation, immersion in $\mathrm{CO}_{2}$-enriched water facilitates heat transfer from the body to the water or from the water to the body. Consequently, immersion in $\mathrm{CO}_{2}$-enriched water raises or reduces body temperature faster than immersion in fresh water. However, it takes time to dissolve $\mathrm{CO}_{2}$ in tap water and because the dissolved $\mathrm{CO}_{2}$ concentration decreases over time, the actual $\mathrm{CO}_{2}$ concentration is likely lower than the stated target concentration. However, it is unclear whether water containing a lower $\mathrm{CO}_{2}$ concentration would also cool the body faster than fresh water after body temperature had been increased.

Methods: Ten healthy males (mean age $=20 \pm 1$ years) participated in the study. Participants were first immersed for $15 \mathrm{~min}$ in a tap water bath at $40^{\circ} \mathrm{C}$ to raise body temperature. They then moved to a tap water or $\mathrm{CO}_{2}$-enriched water bath at $30^{\circ} \mathrm{C}$ to reduce body temperature. The $\mathrm{CO}_{2}$ concentration was set at $500 \mathrm{ppm}$. The present study measured cooling time and cooling rate (slope of the regression line relating auditory canal temperature $\left(T_{\mathrm{ac}}\right)$ to cooling time) to assess the cooling effect of $\mathrm{CO}_{2}$-enriched water immersion.
\end{abstract}

Results: Immersion in $40^{\circ} \mathrm{C}$ tap water caused $T_{\text {ac }}$ to rise $0.64 \pm 0.25^{\circ} \mathrm{C}$ in the tap water session and $0.62 \pm 0.27^{\circ} \mathrm{C}$ in the $\mathrm{CO}_{2}$-enriched water session $(P>0.05)$. During the $30^{\circ} \mathrm{C}$ water immersion, $T_{\text {ac }}$ declined to the baseline within 13 \pm 6 min in tap water and $10 \pm 6$ min in $\mathrm{CO}_{2}$-enriched water $(P>0.05)$. Cooling rates were $0.08 \pm 0.06^{\circ} \mathrm{C} / \mathrm{min}$ in tap water and $0.08 \pm 0.04^{\circ} \mathrm{C} / \mathrm{min}$ in $\mathrm{CO}_{2}$-enriched water $(P>0.05)$.

Conclusions: $\mathrm{CO}_{2}$-enriched water containing $500 \mathrm{ppm} \mathrm{CO}_{2}$ did not cool faster than tap water immersion. This suggests that when the water temperature is $30^{\circ} \mathrm{C}$, a CO${ }_{2}$ concentration of $500 \mathrm{ppm}$ is insufficient to obtain the advantageous cooling effect during water immersion after body temperature has been increased.

Keywords: $\mathrm{CO}_{2}$-enriched water, Body temperature, Cutaneous vasodilation, Cooling, water immersion

\section{Background}

It is well documented that immersion in $\mathrm{CO}_{2}$-enriched water causes cutaneous vasodilation at the immersed body surface [1-7]. This facilitates heat transfer from the body to the water, or from the water to the body. Applying this phenomenon, an earlier study compared

*Correspondence: khayashi@u-shizuoka-ken.ac.jp Junior College, University of Shizuoka, 2-2-1 Oshika, Suruga-ku, Shizuoka 422-8021, Japan the cooling effect of whole-body immersion in $\mathrm{CO}_{2}$-rich (1000 ppm) water with immersion in tap water after passive heating [8]. In that study, it was observed that immersion in $\mathrm{CO}_{2}$-rich water reduced ear canal temperature $\left(T_{\mathrm{ac}}\right)$ about 1.7 times faster than tap water immersion. Similarly, Tanaka et al. [7] evaluated the cooling effect of immersing the forearms in cool water and reported that the decrease in ear canal temperature was slightly greater in $\mathrm{CO}_{2}$-rich water than in tap water. In both of those earlier studies, the $\mathrm{CO}_{2}$ concentration was 
set at $1000 \mathrm{ppm}$ because that concentration is the lowest found in therapeutic springs [5].

However, there are problems associated with preparing artificial $\mathrm{CO}_{2}$-enriched water. For example, it takes time to dissolve $\mathrm{CO}_{2}$ in tap water. With the device used in previous studies, it takes $>20 \mathrm{~min}$ to prepare a full bathtub (about $200 \mathrm{~L}$ ) of $1000 \mathrm{ppm} \mathrm{CO}_{2}$-rich water [2, 8]. In addition, the $\mathrm{CO}_{2}$ concentration gradually decreases over time. Considering actual usage, therefore, it is likely the $\mathrm{CO}_{2}$ concentration in the $\mathrm{CO}_{2}$-enriched water was lower than $1000 \mathrm{ppm}$, at least part of the time. For that reason, it is important to clarify whether a lower concentration $(<1000 \mathrm{ppm})$ of $\mathrm{CO}_{2}$ in the $\mathrm{CO}_{2}$-enriched water immersion can cool a body faster than tap water immersion. Schnizer et al. [6] previously examined the effect of $\mathrm{CO}_{2}$-enriched water on skin blood flow at water temperatures ranging from 22 to $38{ }^{\circ} \mathrm{C}$ and $\mathrm{CO}_{2}$ concentrations ranging from 0 to $4000 \mathrm{ppm}$. They showed that the amount of increase in skin blood flow depended on the $\mathrm{CO}_{2}$ concentration and suggested that the minimal effective concentration is $400-600 \mathrm{ppm}$. However, it is unknown whether water enriched with 400-600 ppm $\mathrm{CO}_{2}$ can actually cool the body faster than tap water after the body temperature has been increased. Therefore, to better understand the concentration dependency of the cooling effect of $\mathrm{CO}_{2}$-enriched water, the present study compared the cooling rates between water enriched with a lower concentration of $\mathrm{CO}_{2}$ and tap water during whole body water immersion after passive heating.

\section{Material and methods \\ Participants}

Ten healthy males (mean age $=20 \pm 1$ (SD) years; height $=168.0 \pm 4.7 \mathrm{~cm}$; weight $=61.4 \pm 7.9 \mathrm{~kg}$ ) participated in the study. The participants were all nonsmokers, and none were taking any medication. The study was approved by the research ethics committee of the University of Shizuoka (\#1-24) and conformed to the provisions of the Declaration of Helsinki. Written informed consent was obtained from all participants.

\section{Experimental design}

Each participant completed two sessions (immersion in tap water and in $\mathrm{CO}_{2}$-enriched water) within a 2-week period in random order. The participants were all asked to abstain from strenuous exercise and from consumption of alcohol during the $24 \mathrm{~h}$ before the experiment. In addition, all participants ate the same meal the night before the experiment and for breakfast on the day of the experiment. The experiment was conducted in the morning. After each participant came to the laboratory, they voided urine, were weighed, put on swimwear, and sat in a chair to rest. During this period, a heart rate (HR) monitor and thermocouples for recording skin temperature were attached. Then, an infrared temperature sensor was inserted into the auditory canal to record the temperature $\left(T_{\mathrm{ac}}\right)$. During the experiments, $T_{\text {ac }}$ data was collected using an infrared temperature sensor (BL100, Techno Next, Chiba, Japan), which was sampled every $1 \mathrm{~s}$ and averaged over 30 -s periods. Skin temperature data were collected using copper constantan thermocouples, which were sampled every $1 \mathrm{~s}$ using a data logger system (DL350, Yokogawa, Tokyo, Japan) and averaged over 30 -s periods. Skin temperatures were collected at four sites (chest, upper arm, thigh, and calf) and used to calculate the weighted mean skin temperature $\left(\overline{\mathrm{T}}_{\mathrm{sk}}\right)[9]$. HR was recorded every $5 \mathrm{~s}$ using a HR monitor (S810i, Polar, Finland) and averaged over 30 -s periods. Figure 1 shows the experimental protocol. While the participants continued to sit in the chair, baseline values for each parameter were measured for 5 $\mathrm{min}$. Once the baseline measurements were complete, the participants moved to a bath and were immersed to the axilla in tap water at $40{ }^{\circ} \mathrm{C}$ for $15 \mathrm{~min}$ to raise their body temperature. The participants then moved to another bath and were immersed to the axilla in tap water or $\mathrm{CO}_{2}$-enriched water at $30{ }^{\circ} \mathrm{C}$ to reduce body temperature. A water temperature of $30^{\circ} \mathrm{C}$ was selected to avoid causing shivering or discomfort. Thermal comfort and thermal sensation were recorded every $5 \mathrm{~min}$ while the participant was immersed in the $30{ }^{\circ} \mathrm{C}$ tap or $\mathrm{CO}_{2}$-enriched water. Thermal comfort was evaluated using a four-point scale (1: comfortable-4: very uncomfortable), while thermal sensation was evaluated using a seven-point scale (1: cold-7: hot) [10]. Because bubbles attach to the body during immersion in $\mathrm{CO}_{2}$-enriched water, the water (both tap water and $\mathrm{CO}_{2}$-enriched water) was stirred at $13 \mathrm{~L} / \mathrm{min}$ to keep the participants unaware of which water they were immersed in. The experiments terminated when any of the following were occurred: (1) $T_{\mathrm{ac}}$ dropped to baseline level, (2) the participants asked to terminate the experiment, or (3) $T_{\mathrm{ac}}$ did not change after more than $3 \mathrm{~min}$. The $\mathrm{CO}_{2}$-enriched water was prepared using a device designed to dissolve $\mathrm{CO}_{2}$ in tap water (SC401, Mitsubishi Chemical Aqua Solutions, Tokyo, Japan) [2, 8]. In previous studies, where the water was enriched with $1000 \mathrm{ppm} \mathrm{CO}_{2}[2,3,5,6,8]$, it took $>20 \mathrm{~min}$ to prepare a full bathtub (about $200 \mathrm{~L}$ ) of $\mathrm{CO}_{2}$-enriched water $[2,8]$. The present study aimed to prepare 400 $600 \mathrm{ppm} \mathrm{CO}_{2}$-enriched water within $<10 \mathrm{~min}$. As a result, the $\mathrm{CO}_{2}$ concentration was maintained at about $500 \mathrm{ppm}$ throughout the experiment. The experiments were carried out in a laboratory maintained at $23-25^{\circ} \mathrm{C}$ and $40-60 \%$ relative humidity. 


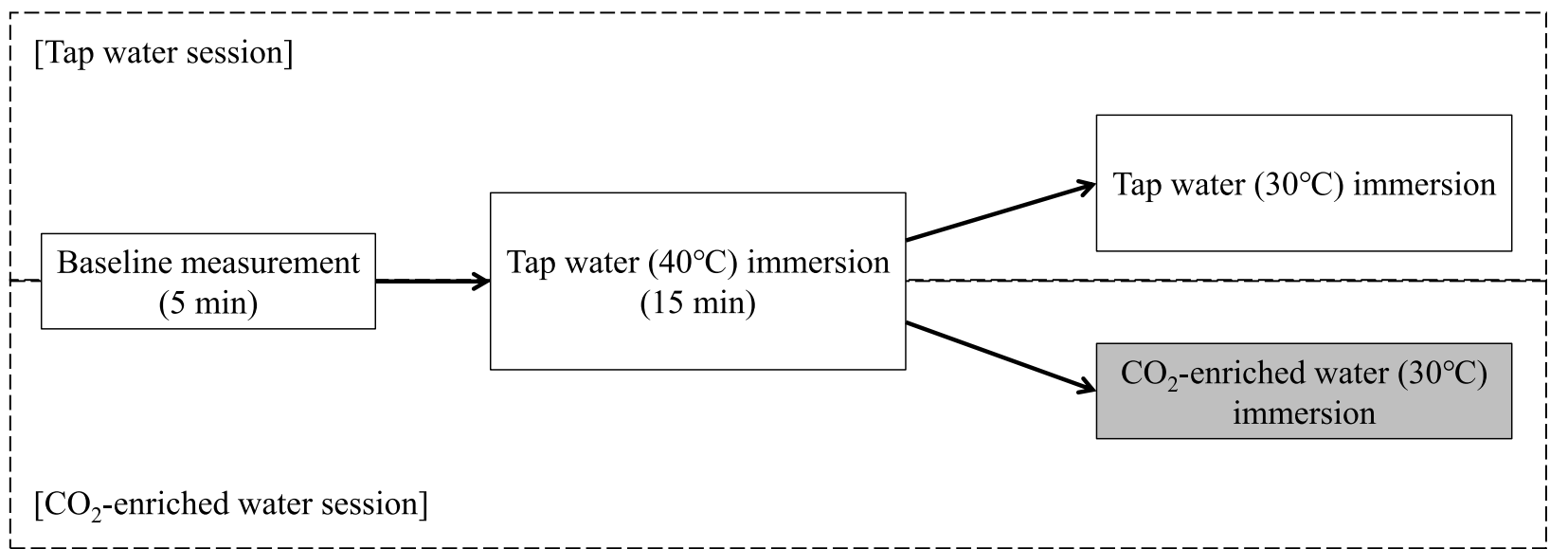

Fig. 1 The experiment protocol. The participants initially sat in a chair for $5 \mathrm{~min}$. During that time, baseline values were measured for each parameter. After the baseline measurements, the participants moved to a bath and were immersed in tap water at $40^{\circ} \mathrm{C}$ for 15 min. The participants then moved to another bath and were immersed in tap water or $\mathrm{CO}_{2}$-enriched water at $30^{\circ} \mathrm{C}$

\section{Statistical analysis}

All values are reported as means \pm SD. Statistical analyses were performed using IBM SPSS Statistics (version 27, IBM Corp., NY, USA). Two-way ANOVA with repeated measures was conducted using time (levels: 1 , $2,3,4,5,6,7,8$, and 9 min during immersion in $30{ }^{\circ} \mathrm{C}$ tap or $\mathrm{CO}_{2}$-enriched water) and condition (levels: tap and $\mathrm{CO}_{2}$-enriched water) as factors. Times at which the numbers of participants were reduced ( $\geq 10 \mathrm{~min}$ ) were not analyzed. Paired $t$ tests were used to compare the tap water and $\mathrm{CO}_{2}$-enriched water sessions with respect to the changes in $T_{\mathrm{ac}}$ from that reached during the immersion in $40{ }^{\circ} \mathrm{C}$ tap water, the cooling times, cooling rates (slope of the regression line between $T_{\mathrm{ac}}$ and cooling time), thermal comfort, and thermal sensation. Values of $P<0.05$ were considered significant.

\section{Results}

At baseline, $T_{\mathrm{ac}}$ was $36.0 \pm 0.5{ }^{\circ} \mathrm{C}$ in the tap water condition and $35.8 \pm 0.6^{\circ} \mathrm{C}$ in the $\mathrm{CO}_{2}$-enriched water condition. Figure 2 shows the time-dependent changes in $T_{\text {ac. }}$. After immersion for $15 \mathrm{~min}$ in the $40{ }^{\circ} \mathrm{C}$ tap water bath, $T_{\text {ac }}$ had risen by $0.64 \pm 0.25^{\circ} \mathrm{C}$ in the tap water condition and by $0.62 \pm 0.27{ }^{\circ} \mathrm{C}$ in the $\mathrm{CO}_{2}$-enriched water condition $(P>0.05)$ (Fig. $2 \mathrm{~A})$. After subsequent immersion in the $30{ }^{\circ} \mathrm{C}$ bath, the time required for $T_{\mathrm{ac}}$ to return to baseline was $13 \pm 6 \mathrm{~min}$ in the tap water condition and $10 \pm 6 \mathrm{~min}$ in the $\mathrm{CO}_{2}$-enriched water condition $(P>0.05)$. The cooling rates were $0.08 \pm 0.06$ ${ }^{\circ} \mathrm{C} / \mathrm{min}$ in the tap water condition and $0.08 \pm 0.04{ }^{\circ} \mathrm{C} /$ min in the $\mathrm{CO}_{2}$-enriched water condition $(P>0.05) . T_{\mathrm{ac}}$ did not return to the baseline level in three participants in the tap water condition and in one participant in the $\mathrm{CO}_{2}$-enriched water condition. During the cooling, there was a significant main effect of cooling time $(F=$ $6.37, P<0.01)$. However, there was no significant main effect of condition $(F=1.41, P=0.24)$ and no interaction between the condition and cooling time $(F=0.23$, $P=0.98)$.

Before heating, $\overline{\mathrm{T}}_{\text {sk }}$ was $31.7 \pm 0.7^{\circ} \mathrm{C}$ in the tap water condition and $31.6 \pm 1.1{ }^{\circ} \mathrm{C}$ in the $\mathrm{CO}_{2}$-enriched water condition. After immersion for $15 \mathrm{~min}$ in the heated bath, $\overline{\mathrm{T}}_{\text {sk }}$ had risen to $38.4 \pm 0.6{ }^{\circ} \mathrm{C}$ in tap water and to $38.4 \pm 0.4{ }^{\circ} \mathrm{C}$ in $\mathrm{CO}_{2}$-enriched water. $\overline{\mathrm{T}}_{\text {sk }}$ rapidly declined during cooling, and there was a significant main effect of cooling time $(F=7.13, P<0.01)$, but there was no significant main effect of condition $(F=$ 2.88, $P=0.09)$ and no interaction between the condition and cooling time ( $F=0.11, P=0.99)$ (Fig. $2 \mathrm{~B})$.

Figure 3 shows the time-dependent changes in HR. Before heating, HR was $75 \pm 6$ beats $/ \mathrm{min}$ in the tap water condition and $75 \pm 5$ beats $/ \mathrm{min}$ in the $\mathrm{CO}_{2}$-enriched water condition. By the end of heating, HR had increased to $96 \pm 6$ beats/min in the tap water condition and to $95 \pm 4$ beats $/ \mathrm{min}$ in the $\mathrm{CO}_{2}$-enriched water condition. HR decreased during cooling in both conditions, and there was a significant main effect of cooling time $(F=7.29, P<0.01)$. On the other hand, there was no significant main effect of condition $(F=$ 2.07, $P=0.15)$ or interaction between condition and cooling time $(F=0.10, P=0.99)$.

Table 1 shows the thermal comfort and sensation reported during cooling. There was no significant between-condition difference in thermal comfort or thermal sensation after 5 min of cooling. 


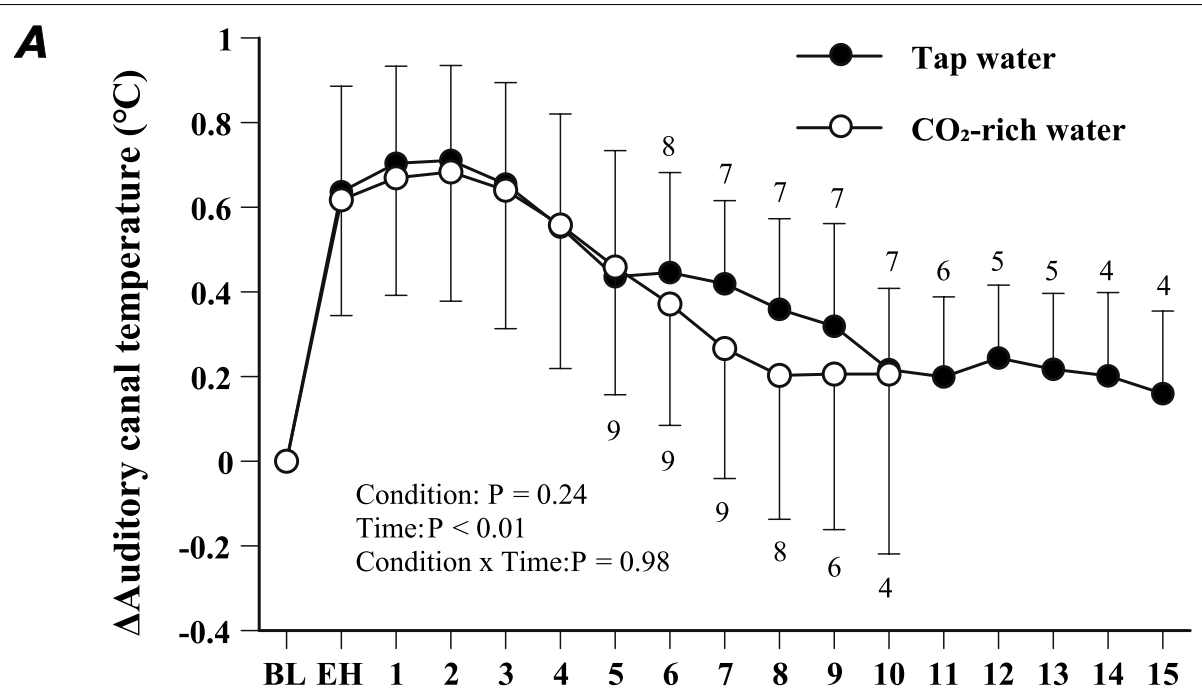

B

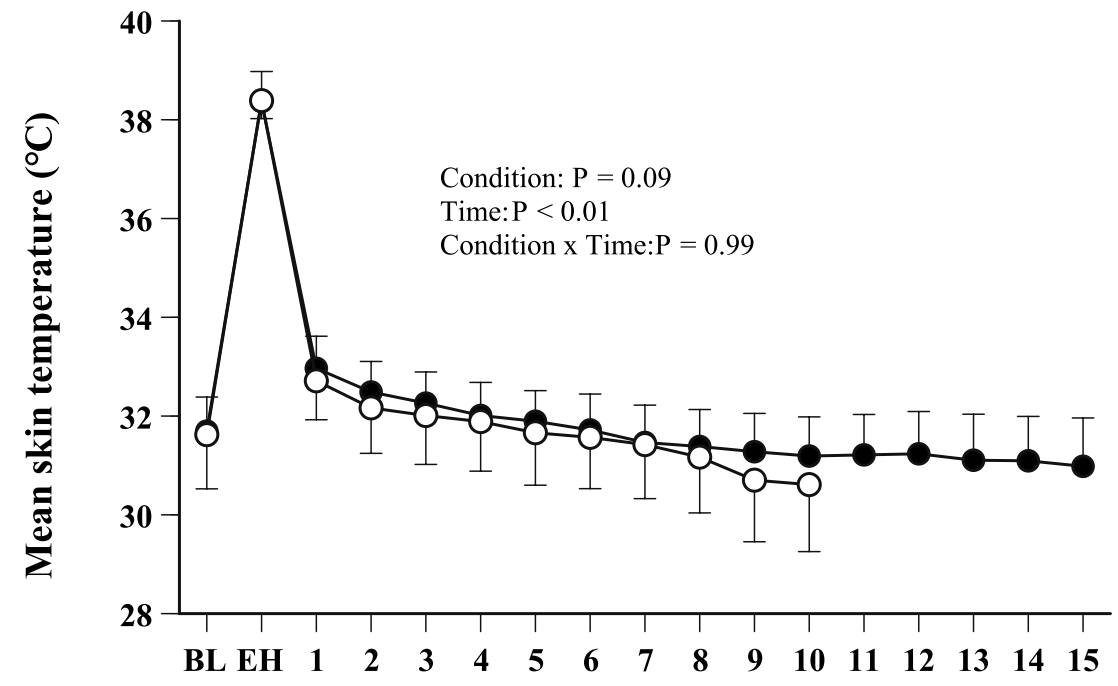

Cooling time (min)

Fig. 2 Time-dependent changes in change in auditory canal temperature $(\mathbf{A})$ and mean skin temperature $(\mathbf{B})$. The numbers adjacent to the symbols in (A) indicate the numbers of participants still immersed at the corresponding time; the numbers in (A) also apply to (B). Condition and time are the two factors considered in the ANOVA; condition $\times$ time is their interaction. BL baseline, EH end of heating

\section{Conclusions}

The present study shows that $\mathrm{CO}_{2}$-enriched water containing $500 \mathrm{ppm} \mathrm{CO}_{2}$ does not facilitate heat transfer from the body to the water. It was previously reported that immersion in $\mathrm{CO}_{2}$-enriched water containing 1000 ppm $\mathrm{CO}_{2}$ cooled the body 1.7 times faster than immersion in tap water [8]. That was not the case with the lower concentration of $\mathrm{CO}_{2}$ used in the present study. Schnizer et al. [6] examined the effect of $\mathrm{CO}_{2}$-enriched water on skin blood flow at different water temperatures $\left(22-38{ }^{\circ} \mathrm{C}\right)$ and $\mathrm{CO}_{2}$ concentrations $(0-4000 \mathrm{ppm})$. They reported that the magnitude of the increase in skin blood flow depended on the $\mathrm{CO}_{2}$ concentration and the water temperature and that the latency of the increase in skin blood flow increased with decreases in water temperature. In addition, Ito et al. [1] examined the effect of water temperature and $\mathrm{CO}_{2}$ concentration on skin blood flow in rats while dissolving $\mathrm{CO}_{2}$ into the freshwater bath during a 20-min water immersion. They reported that skin blood flow gradually increased during the $\mathrm{CO}_{2}$-enriched water immersion and that skin blood flow increased with increases in the dissolved $\mathrm{CO}_{2}$ concentration, even at a water temperature of $23{ }^{\circ} \mathrm{C}$. These results suggest that a $\mathrm{CO}_{2}$ concentration of $500 \mathrm{ppm}$ in water was insufficient 


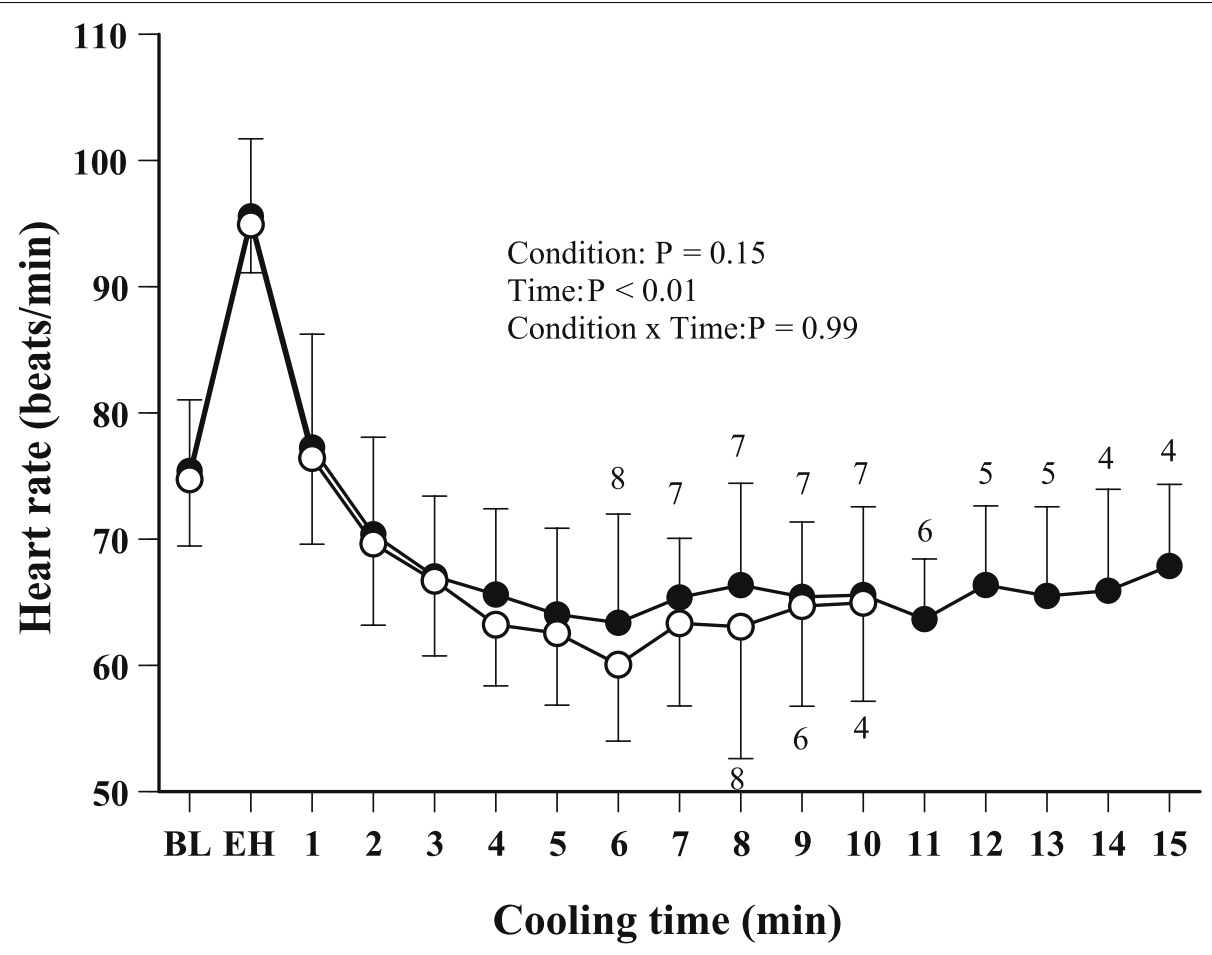

Fig. 3 Time-dependent changes in heart rate. Because heart rate could not be measured in one subject, the data presented are from the remaining nine subjects. The numbers adjacent to the symbols indicate the numbers of participants still immersed at the corresponding time. Condition and time are the two factors considered in the ANOVA; condition $\times$ time is their interaction. $B L$ baseline, EH end of heating

Table 1 Thermal comfort and sensation during cooling

\begin{tabular}{llll}
\hline & $\mathbf{5} \mathbf{~} \mathbf{i n}$ & $\mathbf{1 0} \mathbf{~} \mathbf{i n}$ & $\mathbf{1 5} \mathbf{~} \mathbf{~ i n}$ \\
\hline $\begin{array}{l}\text { Thermal comfort } \\
\quad\end{array}$ & $1.5 \pm 0.5$ & $2.0 \pm 0.8(n=7)$ & $2.3 \pm 1.0(n=4)$ \\
$\quad \begin{array}{l}\text { Tap water } \\
\mathrm{CO}_{2} \text {-enriched water }\end{array}$ & $1.6 \pm 0.7$ & $2.0 \pm 0.8(n=4)$ & - \\
$\begin{array}{l}\text { Thermal sensation } \\
\text { Tap water }\end{array}$ & $2.9 \pm 0.9$ & $2.4 \pm 1.4(n=7)$ & $2.5 \pm 1.3(n=4)$ \\
$\mathrm{CO}_{2}$-enriched water & $2.9 \pm 1.0$ & $3.8 \pm 1.3(n=4)$ & - \\
\hline
\end{tabular}

Thermal comfort scale (1: comfortable-4: very uncomfortable). Thermal sensation scale (1: cold-7: hot). Values are means \pm SD

to facilitate heat transfer from the body during a 10 -min water immersion. Moreover, there was no significant between-condition difference in thermal comfort or thermal sensation, indicating that immersion in water containing a low $\mathrm{CO}_{2}$ concentration after passive heating does not alleviate the sensation of discomfort. Previous studies reported that immersion in $\mathrm{CO}_{2}$-enriched water produced a warmer, more comfortable sensation than immersion in fresh water [2, 5, 8]. Given the present observations that there were no significant differences in $\Delta T_{\text {ac }}$, thermal comfort, or thermal sensation, it is suggested that, at $500 \mathrm{ppm}$, there is insufficient diffusion of
$\mathrm{CO}_{2}$ into cutaneous blood vessels to exert a beneficial effect.

On the other hand, Sato et al. [4] reported that when participants were immersed in a hot bath, even $100 \mathrm{ppm}$ $\mathrm{CO}_{2}$ enhanced skin blood flow and sweating measured at the chest as compared to freshwater immersion. The difference between the present study and Sato's study is water temperature. In their study, measurements of skin blood flow were made at a water temperature of $40{ }^{\circ} \mathrm{C}$. During immersion in hot water, even fresh water, skin blood flow is augmented [4]. Although skin blood flow was not measured in the present study, the water temperature was set at $30{ }^{\circ} \mathrm{C}$, and $\overline{\mathrm{T}}_{\text {sk }}$ was always lower than $34{ }^{\circ} \mathrm{C}$ during immersion. This suggests that the degree of cutaneous vasodilation was almost certainly smaller than in Sato's study. Previous studies $[1,6]$ reported that the magnitude of the increase in skin blood flow during $\mathrm{CO}_{2}$-enriched water immersion was dependent on the water temperature. It is therefore possible that the amount of $\mathrm{CO}_{2}$ diffusing into the cutaneous blood vessels was higher in those earlier studies than in the present study.

In summary, the results of the present study suggest that immersion in water containing a low concentration of $\mathrm{CO}_{2}(500 \mathrm{ppm})$ does not cool the body faster than 
immersion in tap water after passive heating, nor does it alleviate the sensation of discomfort when the water temperature is set at $30{ }^{\circ} \mathrm{C}$. These observations suggest that a higher $\mathrm{CO}_{2}$ concentration is necessary to obtain the advantageous cooling effect and alleviate discomfort during water immersion after hyperthermia. For practical application, the present results suggest that a high concentration of $\mathrm{CO}_{2}$ in water is necessary to enhance body temperature reduction, even if it takes time to prepare, and that it is necessary to maintain that high $\mathrm{CO}_{2}$ concentration throughout the immersion period.

\section{Abbreviations}

ANOVA: Analysis of variance; $\mathrm{CO}_{2}$ : Carbon dioxide; $\mathrm{HR}$ : Heart rate; $T_{\mathrm{ac}}$ : Auditory canal temperature; $\overline{\mathrm{T}}_{\mathrm{sk}}$ : Mean skin temperature.

\section{Acknowledgements}

I sincerely thank the volunteer participants for participating in this study. I appreciate the help of Medical support center of the University of Shizuoka for medical support. I also greatly appreciate the help of Dr. William Goldman (English editing and critical comments).

\section{Author's contributions}

The author conceived and designed the research, conducted experiment, analyzed data, drafted manuscript, and approved the final version of the manuscript. The author(s) read and approved the final manuscript.

\section{Funding}

This study was supported by JSPS KAKENHI Grant Number 18K10917.

\section{Availability of data and materials}

The datasets used and/or analyzed during this study are available from the corresponding author on reasonable request.

\section{Declarations}

\section{Ethics approval and consent to participate}

The study was approved by the Research Ethics Committee of the University of Shizuoka (\#1-24). Written informed consent was obtained from all participants.

\section{Consent for publication}

The author approved the final version of the manuscript and submission to the Journal of Physiological Anthropology.

\section{Competing interests}

The author declares no competing interests.

Received: 10 May 2021 Accepted: 8 November 2021

Published online: 17 November 2021

\section{References}

1. Ito T, Moore Jl, Koss MC. Topical application of $\mathrm{CO}_{2}$ increases skin blood flow. J Invest Dermatol. 1989;93:259-62.

2. Nishimura N, Sugenoya J, Matsumoto T, Kato M, Sakakibara H, Nishiyama $T$, et al. Effects of repeated carbon dioxide-rich water bathing on core temperature, cutaneous blood flow and thermal sensation. Eur J Appl Physiol. 2002:87:337-42.

3. Ogoh S, Washio T, Suzuki K, Ikeda K, Hori T, Olesen ND, et al. Effect of leg immersion in mild warm carbonated water on skin and muscle blood flow. Physiol Rep. 2018;6:e13859.

4. Sato M, Sugenoya J, Sato H, Kudoh M, Nishimura N, Matsumoto T, et al. Effects of $\mathrm{CO}_{2}$-bath immersion (100 ppm) on thermoregulatory responses in humans. J Therm Biol. 2004;29:805-8.

5. Sato M, Kanikowska D, I wase S, Nishimura N, Shimizu Y, de Chantemele $E B$, et al. Effects of immersion in water containing high concentrations of $\mathrm{CO}_{2}\left(\mathrm{CO}_{2}\right.$-water $)$ at thermoneutral on thermoregulation and heart rate variability in humans. Int J Biometeorol. 2009;53:25-30.

6. Schnizer W, Erdl R, Schöps P, Seichert N. The effect of external $\mathrm{CO}_{2}$ application on human skin microcirculation investigated by laser Doppler flowmetry. Int J Microcirc Clin Exp. 1985;4:343-50.

7. Tanaka Y, Nagano H, Taimura A. Body cooling effects of immersion of the forearms in high-concentration artificial carbonic acid water at $25^{\circ} \mathrm{C}$. J Physiol Anthropol. 2020;39:2.

8. Hayashi K. A novel cooling method using carbon dioxide-rich water after passive heating. J Therm Biol. 2021;96:102843.

9. Ramanathan NL. A new weighting system for mean surface temperature of the human body. J Appl Physiol. 1964;19:531-3.

10. Hardy JD. Thermal comfort: skin temperature and physiological thermoregulation. In: Hardy JD, Gagge AP, Stolwijk AJ, editors. Physiological and behavioral temperature regulation. Springfield: Thomas; 1970. p. 856-73.

\section{Publisher's Note}

Springer Nature remains neutral with regard to jurisdictional claims in published maps and institutional affiliations.

\footnotetext{
Ready to submit your research? Choose BMC and benefit from:

- fast, convenient online submission

- thorough peer review by experienced researchers in your field

- rapid publication on acceptance

- support for research data, including large and complex data types

- gold Open Access which fosters wider collaboration and increased citations

- maximum visibility for your research: over $100 \mathrm{M}$ website views per year
}

At BMC, research is always in progress.

Learn more biomedcentral.com/submissions 